\title{
Improving the Professional Risk Management System for Methane and Coal Dust Explosions Using a Risk-based Approach
}

\author{
Tatiana Tyuleneva ${ }^{1,2, *}$,Evgeny Kabanov ${ }^{3}$, Marat Moldazhanov ${ }^{4}$, and Evgeny Plotnikov ${ }^{5}$ \\ ${ }^{1}$ T.F. Gorbachev Kuzbass State Technical University, Department of Management Accounting and \\ Analysis, 650000 Kemerovo, 28 Vesennya st., Russian Federation \\ ${ }^{2}$ Branch of T.F. Gorbachev Kuzbass State Technical University in Prokopyevsk, Department of \\ Social and Humanitarian Disciplines, 653049 Prokopyevsk, 19a Nogradskaya st., Kemerovo region - \\ Kuzbass, Russian Federation \\ ${ }^{3}$ Saint-Petersburg Mining University, Department of Industrial Safety, 199106 Saint-Petersburg, 2 \\ Line 21 V. I., Russian Federation \\ ${ }^{4}$ Kazakh Humanitarian-Law Innovative University, Department of Finance and Accounting, 11 \\ Mangilik el st., Semey, East Kazakhstan region, 071400, Republic of Kazakhstan \\ ${ }^{5}$ T.F. Gorbachev Kuzbass State Technical University, Mezhdurechensk Branch, 652881 \\ Mezhdurechensk, 36 Stroiteley st., Russian Federation
}

\begin{abstract}
The regular nature of emergencies and accidents indicates the need to use progressive approaches to ensuring industrial safety and labour protection of employees of the extractive industry. The use of a retrospective analysis does not allow us to take into account dangerous factors that have not been detected by the accumulated experience, and this disadvantage can be eliminated by the principles of a priori analysis, which takes into account the potential risks for this system and the factors of their occurrence in the context of a risk-based approach. The problem of studying the occupational risks of the negative impact of hazardous and harmful production factors on personnel as a result of accidents at coal mining enterprises is the area of joint functioning of the occupational health and safety management system and the industrial safety management system. In order to meet the requirements for the analysis and forecasting of occupational injury risks in methane and dust explosions under conditions of uncertainty of the initial data, there is a need for a methodological approach based on the modeling of fuzzy logical inference with a hierarchical structure. This article describes a methodology that will ensure the implementation of the requirements in the field of complex analysis and forecasting of occupational injury risk in methane and dust explosions with the detection of dangerous situations and areas, as well as take into account the results of complex analysis and forecasting.
\end{abstract}

\section{Introduction}

\footnotetext{
* Corresponding author: krukta@mail.ru
} 
Underground coal mining is always combined with a complex of harmful production factors, the influence of which is caused primarily by mining and geological conditions, the use of high-performance machines and mechanisms, and the significant intensity of the work performed on mining and sinking. Also, the assessment of industrial safety and labor protection conditions is influenced by the quality of engineering and technical decisions made, the state of technological discipline and the level of professional competence of performers [1-3].

The use of traditional methods of ensuring safety is characterized by the development of regulations for the organization of work of a coal mining enterprise. But the regular nature of emergencies and accidents indicates the need to use progressive approaches to ensuring industrial safety and labor protection of employees of the extractive industry. The industrial safety regulations are mainly developed a posteriori-based on the results of a study of cases that have already occurred and taking into account the worst-case scenario of the situation, and by their nature they are requirements and recommendations for minimizing the threats of similar events in the future. The use of retrospective analysis does not make it possible to take into account dangerous factors that are not detected by the accumulated experience, which is of great importance for the safety of working conditions created in a dynamic and subject to a set of specific factors in the production environment.

This disadvantage can be eliminated by the principles of a priori analysis, which takes into account the potential risks for this system and the factors of their occurrence. Its implementation consists in conducting a systematic analysis of threats, assessing and predicting their occurrence in a risk-based approach. The use of a risk-based approach ensures the detection of threats that are likely to occur in the system under study; the study of scenarios that result in the identified threats; detection of the most significant events and factors contributing to the occurrence of undesirable events; assessment of the severity of the consequences of undesirable events; development of draft solutions based on the results of the analysis and aimed at minimizing the identified threats. The risk-based approach has demonstrated high efficiency in the foreign practice of analysis, on the basis of this, this direction was evaluated as relevant in the Russian professional practice.

\section{Theory of Experimental Research}

To select a methodology for assessing the occupational risk of fatal injuries to employees of a coal mining enterprise during methane and dust explosions, a study of the methodological basis for risk assessment was carried out, which revealed the areas of its use, depending on the available array of information for statistical research and the availability of data for modeling.

To study the individual risk of injuries, an analysis of the acts of industrial investigation of the causes of methane explosions, outbreaks and ignitions over 12 years at 98 coal mining enterprises [3] was performed, taking into account their following parameters: the number of methane explosions noted, the average number of personnel, the number of fatally injured personnel, the relative and absolute gas content, the depth of field development, daily production in kind, the development system, the method and scheme of ventilation, the degree of danger of the coal seam due to spontaneous combustion, dust explosives, the period of operation of the coal mining enterprise in the analyzed year - as well as risk parameters: the average annual number of methane explosions of the observed individual risk of fatal injuries from each of them. According to the results of the study, it was revealed that the use of methods of statistical analysis of occupational injury risk is limited by the uncertainty of the initial information. In particular, the relatively low values of the model's determination coefficient indicate the significance of the impact of unaccounted factors, and their detection requires updating the database of statistical observations of accidents and injuries that take 
into account risk factors. In a situation of information uncertainty, there is a need to apply the results of mathematical modeling and expert assessments to study unaccounted factors. At the same time, the task of quantifying the factors that determine the intensity of methane release into underground workings and the diameter of the zone affected by explosions of a methane-dust-air mixture is of practical interest.

Cases of injuries at coal mining enterprises caused by methane and dust explosions occur when the conditions for their occurrence and the subsequent influence of dangerous factors are realized, so the level of occupational risk of injuries should be determined taking into account the results of assessing the probability of their damaging effect. According to the classification of hazardous production factors of methane and dust explosions in coal mine workings [4], these include, first, factors of physical impact on the body - shock air wave and thermal radiation during combustion and ignition, and, second, factors of chemical impact-gaseous toxic compounds formed during combustion. According to the results of the study of group accidents [5-8] at the coal mining facilities of the Kemerovo region for 15 consecutive years, it was revealed that the largest number of fatal injuries is due to the influence of air wave impacts during an explosion, which allowed us to put this factor as the main factor under study that determines the amount of damage when analyzing and predicting the occupational risk of injuries in methane and dust explosions. To achieve the objectives of the occupational health and safety management system to minimize occupational risks and ensure the safety of work, priorities in solving risk management tasks are determined depending on the standard conditions of deviations from them in connection with emergency situations. In particular, the risks of accidents at coal mining enterprises are included in the list of risks to the life and health of people and are subject to study in order to quantify the levels of occupational risks. The requirements for the actual or potential production environment are also established when performing an assessment of professional risks, based on the results of which the risks of possible accidents in the industrial safety management system are predicted. Thus, the task of studying occupational injury risks under the influence of hazardous production factors - methane and dust explosions - is to ensure the interconnectedness of the functioning of the occupational health and safety management system and the industrial safety management system [9], shown in Figure 1.

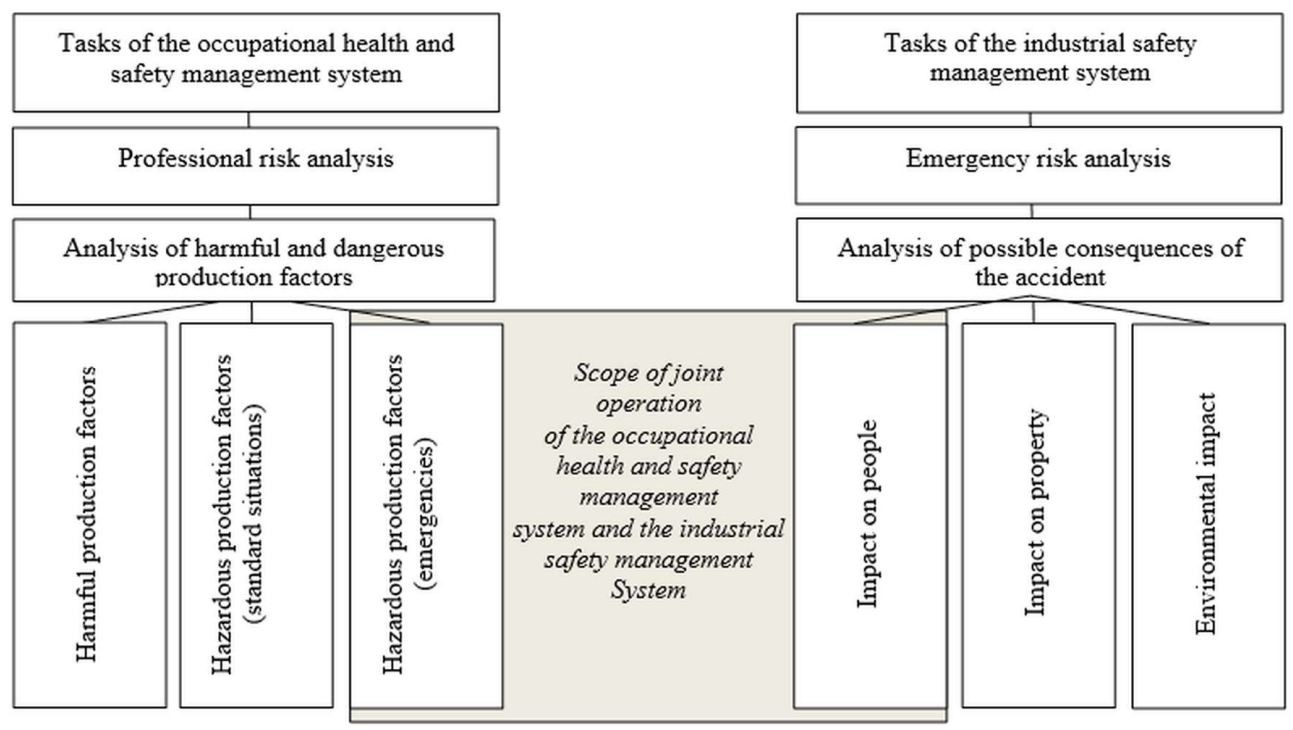

Fi. 1. The scope of joint operation of the occupational health and safety management system and the industrial safety management system of a coal mining enterprise [9]. 
In addition, the requirements for the uniformity of the principles of ensuring the safety of mining operations and supervision of compliance with the requirements of industrial safety and labor protection at coal mining enterprises are regulated by the Model regulation on the industrial safety and labor protection management system.

The solution of the problem of analyzing and predicting the occupational risk of injuries at coal mining enterprises in the event of methane and dust explosions in the context of the functioning of the industrial safety and labor protection management system involves taking into account the results of studying the risks of accidents in the event of methane and dust explosions and applying methods based on the development of a fuzzy inference model.

\section{Results and Discussion}

In order to meet the requirements for detecting potentially dangerous areas affected by the shock waves of methane and dust explosions, the sections of the underground mining system are differentiated by comparing the ranked sets of risk and protection factors. This action allows to identify a set of priority tasks to minimize professional risk by pinpointing the prevailing risk factors. The sequence of implementation of the methodology for complex analysis and forecasting of occupational injury risk in methane and dust explosions involves the following stages [10-13].

First, the collection of initial and structuring information about a set of $\mathrm{n}$ factors in various sections of the mining system, which includes: assessment of mining-geological and miningtechnical factors that characterize the magnitude of potential threats based on the actual data obtained in the activities of the coal mining enterprise (from them by in situ measurement methods and obtained in the course of laboratory studies); assessment of organizational factors that reflect the degree of compliance with safety rules and identified during control measures of the state of safety; assessment of subjective factors that reflect the degree of labor discipline and are measured by methods or based on the results of expert evaluation.

In Second, the study of the formed array of information and the classification of the system of mine workings and their sections, depending on the results of control measures according to the criterion of difference between the ranked data sets.

Third, the selection of a mine or its site, the study of an ordered set of data using a fuzzy inference model based on the cyclic repetition of the algorithm according to the generated database of indicators and obtaining output indicators: quantitative assessment of the risk of a primary explosion of a methane-dust-air mixture in a mine or its site; quantitative assessment of the risk of a secondary explosion of a dust-air mixture; quantitative assessment of the risk of injuries from shock wave pressure during primary and secondary explosions in a mine or its site; quantification of $\mathrm{p}$ variables for the analysis of probable scenarios and factors of occurrence of dangerous events. The third stage is cyclically repeated for the remaining mine workings and / or their sections.

Fourth, the assessment of occupational risk indicators for mine workings or their sections based on their comparison with the acceptable risk standards determined in the course of an expert study.

Fifth, the identification of the number of mine workings or their sections that are located within the radius of the damaging effect of the shock wave of the explosion, the values of the occupational risk of which prevail over the permissible ones.

Sixth, the quantitative assessment of internal variables for mine workings or their sections by levels of hierarchy and the prevailing probability of development of the scenario of adverse events as a result of the damaging effect of the explosion of a methane-dust-air wave.

Seventh, the study of the scenario of the development of an unfavorable event for a mining operation or its site and the study of the main factors of its occurrence. 
The use of this technique will provide an opportunity to study and predict the occupational risk of injuries in methane-dust-air mixture explosions, during which the interrelated risk and protection factors are taken into account and investigated, and dangerous situations caused by the damaging impact of the methane and dust shock wave are predicted. The results of the study of the prevailing scenarios for the development of adverse events will make it possible to determine the list of the main causes of injuries that are important for the operational implementation of preventive measures against injuries. Thus, the application of the methodology is necessary for the introduction of a risk-based approach, the proper level of information support, ensures compliance with the requirements for the analysis and forecasting of professional risks and their regulation [14], with the observance of a point-bypoint and individual approach to the selection and application of measures to improve the safety of the personnel of the coal mining enterprise.

To study the possibility of using this technique in professional risk management, the principles of improving the effectiveness of this system were evaluated, the results of which are presented in Table 1 [15].

\begin{tabular}{|c|c|c|c|c|c|c|}
\hline \multicolumn{3}{|c|}{$\begin{array}{l}\text { Tasks of the occupational health and } \\
\text { safety management system }\end{array}$} & & \multicolumn{3}{|c|}{$\begin{array}{l}\text { Tasks of the industrial safety } \\
\text { management system }\end{array}$} \\
\hline \multicolumn{3}{|c|}{ Professional risk analysis } & & \multicolumn{3}{|c|}{ Emergency risk analysis } \\
\hline \multicolumn{3}{|c|}{$\begin{array}{l}\text { Analysis of harmful and dangerous } \\
\text { production factors }\end{array}$} & & \multicolumn{3}{|c|}{$\begin{array}{c}\text { Analysis of possible consequences of } \\
\text { the accident }\end{array}$} \\
\hline 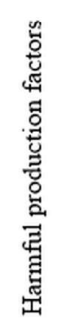 & 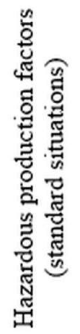 & 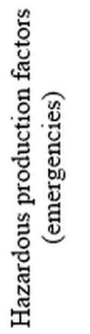 & $\begin{array}{c}\text { Scope of joint } \\
\text { operation } \\
\text { of the occupational } \\
\text { health and safety } \\
\text { management } \\
\text { system and the industrial } \\
\text { safety management } \\
\text { System }\end{array}$ & 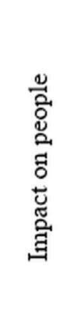 & 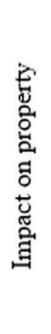 & 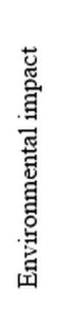 \\
\hline
\end{tabular}

Table 1. The study of the possibility of applying the methodology of complex analysis and forecasting of occupational risk in the creation of a professional risk management system at a coal mining enterprise [15].

\begin{tabular}{|c|c|}
\hline $\begin{array}{c}\text { Principles of improving the effectiveness of } \\
\text { the professional risk management system }\end{array}$ & $\begin{array}{c}\text { Opportunities for applying an integrated } \\
\text { approach to research }\end{array}$ \\
\hline $\begin{array}{c}\text { Ensuring evidence of the implementation of the } \\
\text { stated goals, improving the efficiency of the } \\
\text { production process }\end{array}$ & $\begin{array}{c}\text { Selection and implementation of a set of } \\
\text { organizational and technical measures to } \\
\text { achieve the goals in the field of labor } \\
\text { protection, taking into account the results of } \\
\text { the study of occupational risks }\end{array}$ \\
$\begin{array}{c}\text { Ensuring the possibility of continuous } \\
\text { improvement of the organization and risk } \\
\text { management through the implementation of the } \\
\text { developed strategies }\end{array}$ & $\begin{array}{c}\text { Occupational risk analysis based on a } \\
\text { universal approach to organizational } \\
\text { processes implemented at various }\end{array}$ \\
\hline $\begin{array}{c}\text { Implementation in the organizational processes } \\
\text { associated with the project at all levels and stages } \\
\text { of its life cycle }\end{array}$ & \\
\hline
\end{tabular}




\begin{tabular}{|c|c|}
\hline $\begin{array}{c}\text { Information support for decision-making at each } \\
\text { stage of the project life cycle, identification of } \\
\text { existing risks and identification of priority and } \\
\text { alternative measures }\end{array}$ & $\begin{array}{c}\text { management levels and life cycle stages to } \\
\text { ensure occupational safety }\end{array}$ \\
\hline $\begin{array}{l}\text { Ensuring the ability to assess, capture and } \\
\text { minimize uncertainties }\end{array}$ & $\begin{array}{l}\text { Minimization of information uncertainty } \\
\text { through expert analysis of complex } \\
\text { formalizable dependencies and presentation of } \\
\text { research results in the form of fuzzy sets used } \\
\text { to model the degree of uncertainty in the } \\
\text { structure of fuzzy numbers }\end{array}$ \\
\hline $\begin{array}{l}\text { Ensuring the application of relevant and reliable } \\
\text { project solutions, improving the efficiency of } \\
\text { project management through the use of a } \\
\text { systematic and operational approach to risk } \\
\text { management and the formation of their effective } \\
\text { infrastructure }\end{array}$ & \multirow{2}{*}{$\begin{array}{l}\text { Ensuring the application of a process } \\
\text { approach in management, based on a } \\
\text { systematic analysis of professional risks and } \\
\text { continuous improvement of models for } \\
\text { calculating quantitative risk indicators, aimed } \\
\text { at detecting and registering factors and their } \\
\text { relationships }\end{array}$} \\
\hline $\begin{array}{l}\text { Providing flexibility to change in order to } \\
\text { identify new risks and review previously } \\
\text { identified risks in order to quickly respond to } \\
\text { threats in a changing external and internal } \\
\text { environment }\end{array}$ & \\
\hline $\begin{array}{c}\text { Fixing the most reliable and accessible data in } \\
\text { the risk management system - technical } \\
\text { assessment, tests, observations, expert } \\
\text { assessments }\end{array}$ & \multirow{2}{*}{$\begin{array}{l}\text { Parallel application of the results of statistical, } \\
\text { probabilistic and expert assessments in the } \\
\text { complex analysis of professional risks, as well } \\
\text { as collective expert assessments to minimize } \\
\text { the subjectivity of the results }\end{array}$} \\
\hline $\begin{array}{l}\text { Ensuring the necessary level of prompt } \\
\text { participation of stakeholders at all levels of the } \\
\text { hierarchy for the integrated consideration of } \\
\text { opinions, improving the effectiveness and } \\
\text { relevance of risk management }\end{array}$ & \\
\hline $\begin{array}{l}\text { Identification of design features, the degree of } \\
\text { uncertainty and complexity of the operations } \\
\text { performed }\end{array}$ & \multirow{2}{*}{$\begin{array}{l}\text { Registration of a complex of professional risk } \\
\text { factors with the possibility of modeling } \\
\text { information uncertainty in the context of } \\
\text { expert assessments }\end{array}$} \\
\hline $\begin{array}{l}\text { Assessment of the impact of subjective factors } \\
\text { on the achievement of project objectives and the } \\
\text { effectiveness of risk management processes }\end{array}$ & \\
\hline
\end{tabular}

The data presented in the table indicate the possibility of using the described methodology as a tool for analyzing and predicting risks in order to obtain data that are the basis for developing effective management decisions to preserve the life and health of personnel. The potential opportunities for the development of the professional risk management system are confirmed by the principle of constant and systematic replenishment of the knowledge base, which is of great importance in the study of the dynamically changing production environment of coal mining enterprises and ensures compliance with the requirements of regulatory acts to improve risk assessment procedures. 


\section{Conclusion}

The problem of studying the occupational risks of the negative impact of hazardous and harmful production factors on personnel as a result of accidents at coal mining enterprises is the area of joint functioning of the occupational health and safety management system and the industrial safety management system. To solve this problem, a method is described, the use of which will ensure the fulfillment of the requirements in the field of complex analysis and forecasting of the occupational risk of injuries in methane and dust explosions with the detection of dangerous situations and areas, as well as take into account the results of complex analysis and forecasting. The methodology can be applied to the organization of a continuous process of risk identification according to the following procedures: routine inspection in case of changes in mining-geological and mining-technical conditions and mining production technology; unscheduled inspection when replacing technological equipment for mining operations, using the services of contractors at a coal mining enterprise; periodic report of the industrial safety and labor protection division on identification, assessment and risk management to the managing body.

\section{References}

1. A. Kabyl, M. Yang, R. Abbassi, S. Li, Process Safety and Environmental Protection: Transactions of the Institution of Chemical Engineers, Part B, 139 (2020)

2. T. Tyuleneva, Proceedings of the 9th China-Russia Symposium "Coal in the 21st Century: Mining, Intelligent Equipment and Environment Protection" (Atlantis Press, Paris, 2018)

3. R. Abubakirov, M. Yang, N. Khakzad, Process Safety and Environmental Protection: Transactions of the Institution of Chemical Engineers, Part B, 134 (2020)

4. T.V. Kiseleva, V.G. Mikhailov, G.S. Mikhailov, IOP Conf. Series: Earth and Env. Sci. 84, 012044 (2017)

5. T. Tyuleneva, M. Moldazhanov, E3S Web Conf., 17404061 (2020)

6. B. Nowrouzi-Kia, B. Gohar, J. Casole, C. Chidu, J. Dumond, A. McDougall, Work, 1, 60 (2018)

7. L. Khairullina, G. Starikova, E. Bulgakova, N. Mamaeva, I. Nordman, E3S Web Conf. 21, 05013 (2020)

8. V. Mikhailov, V. Karasev, G. Mikhailov, E3S Web Conf., 41, 02015 (2018)

9. D. Passmore, C. Chae, Y. Kustikova, R. Baker, J. H.Yim, MATEC Web Conf. 45, 06020 (2018)

10. S.G. Gendler, A.M. Grishina, E.A. Kochetkova, Eurasian Mining, 2, 35-39 (2017)

11. T. Tyuleneva, E3S Web Conf. 174, 04019 (2020)

12. M. Rudakov, E. Gridina, J. Kretschmann, Sustainability, 13(2), 1-14 (2021)

13. B. Kobylianskyi, H. Mykhalchenko Mining of Mineral Deposits, 2, 14 (2020)

14. D.Y. Savon, A.V. Aleksakhin, O.O. Skryabin, A.A. Goodilin, Eurasian Mining, 2, 1 (2020)

15. A. Gembalska, Kwiecień Conf. Proceed. 1, 429-436 (2020) 